\title{
DESIGN OF ATOMIZERS AND BURNERS FOR COAL-WATER SLURRY COMBUSTION
}

\author{
Grant Number: DE-FG22-95PC95105 \\ Progress Report for Period 10/1/96 - 12/31/96 \\ Adel Mansour and Norman Chigier \\ Department of Mechanical Engineering \\ Carnegie Mellon University \\ Pittsburgh, PA 15213
}

A review of the results of the current period is included. Section 1 summarizes the progress that was made during the current period. Section 2 discusses the activities planned for the next period.

\section{CURRENT PERIOD PROGRESS REPORT}

The spray characteristics of the double-concentric air assist atomizer have been explored using the Greenfield digital spray analyzer. Prior to utilizing non-Newtonian fluids to simulate coal-water slurries, water was used for the initial survey. The improved performance of the double concentric air assist atomizer, as measured by the total amount of air required to generate a particular average droplet size, was demonstrated.

\section{The Double concentric Air Assist Atomizer}

The double-concentric atomizer is similar to a standard twin-fluid atomizer, see Fig. 1. The outer air flow passage is an annulus surrounding the central circular liquid tube. In the double concentric air assist atomizer, a second air passage is fitted within the liquid supply tube, transforming it into an annulus as well. The flow rates of the liquid and both air flows can be independently controlled. Air is injected inside the liquid, thus resulting in annular liquid sheets and ligaments. The ligaments are further atomized by the outer air flow. Variations in air and liquid mass ratio have been made. The central air mass flow rate and outer air mass flow rate have been varied. This resulted in variations in central air and outer air velocities, central air and outer air Weber number, and central air to outer air mass flow ratios. The liquid flow rate was also varied. 
Greenfield Digital Spray Analyzer

The Greenfield spray analyzer was used to make droplet size measurements. The measurements of droplet sizes are made with computer analysis of an image from a CCD camera. The droplets need not be either transparent or spherical. The droplets must, however, fit completely within the image borders. Out of focus droplets are rejected by an algorithm within the software. The primary limits on the droplet size measurements are minimum and maximum drop sizes and maximum velocity constraints. If the droplet is too large to be contained completely within the image frame, it cannot be analyzed. If the droplet is too small, the number of pixels will be insufficient for analysis and will be rejected. The duration of the flash from the strobe is only sufficient to freeze the motion of droplets with a velocity of less than $35 \mathrm{~m} / \mathrm{s}$. These system limitations constraint the flow conditions that were analyzed to sonic conditions for the inner air and a limit of $200 \mathrm{~m} / \mathrm{s}$ for the outer air. Droplet size measurements were performed at a distance of $20 \mathrm{~cm}$ downstream from the atomizer exit. At this distance, the velocity of the droplets has decayed to values below $35 \mathrm{~m} / \mathrm{s}$ and thus the Greenfield measurements were possible.

The Greenfield Instrument uses a rectangular box as the probe volume and the size depends on the optical settings that are chosen. For the present investigation the area was $5.3 \times 3.98 \mathrm{~mm}$ and the depth was $2 \mathrm{~mm}$. The shadow of individual droplets are focused onto a CCD array which consists of $640 \mathrm{X} 480$ pixels, providing a resolution of 8.3 $\mu \mathrm{m} / \mathrm{pixel}$. Thus, the measurement dynamic range is defined approximately between $32 \mu \mathrm{m}$ and $4000 \mu \mathrm{m}$. Note that the minimum droplet size that was measured is $32 \mu \mathrm{m}$. This is owing to the fact that a minimum of 4 pixels are required to successfully measure droplet size. Thus all measurements were biased towards sampling the larger droplets which have a predominant effect on combustion performance.

\section{Spray Analysis and Experimental Conditions}

An analysis has been made of the flow conditions in the inner and outer air tubes by applying isentropic flow assumptions. The theoretical air mass flow rate can be expressed in terms of air properties at the nozzle exit.

$$
\frac{m_{t h}}{A}=P_{1} M_{1} \sqrt{\frac{\gamma}{R T_{1}}}
$$

in which A represents the nozzle exit area, and the nozzle exit Mach number, $\mathrm{M}_{1}$, is given for a perfect gas by 


$$
M_{1}=\sqrt{\left\langle\left(\frac{P_{0}}{P_{1}}\right)^{\frac{\gamma-1}{\gamma}}-1\right\rangle\left(\frac{2}{\gamma-1}\right)}
$$

where $\mathrm{P}_{\mathrm{O}}$ denotes stagnation pressure and the subscript "1" refers to properties at the nozzle exit. For air the specific heat ratio is $\gamma=1.4$ and the gas constant $\mathrm{R}=287 \mathrm{~J} / \mathrm{kg} \mathrm{K}$. The variations of the specific air mas flux $\mathrm{m}_{\mathrm{th}} / \mathrm{A}$ and the nozzle exit mach number $\mathrm{M}_{1}$ are plotted as a function of stagnation pressure $\mathrm{P}_{\mathrm{O}}$ in Fig. 2. Based on isentropic flow assumptions, the stagnation pressure $\mathrm{P}_{\mathrm{oc}}$, at which flow choking is initiated, was calculated to be $191.5 \mathrm{kPa}$. With a further increase in stagnation pressure the exit Mach number remains unity but the air density increases progressively due to compression, and thus the air mass flux continues to increase.

The discharge coefficient for the central air nozzles tube was determined as a function of air stagnation pressure. The actual air mass flow rate $m_{a}$ was measured using rotameter. The discharge coefficients for air nozzles are determined from the expression, $\mathrm{C}_{\mathrm{d}}=\mathrm{m}_{\mathrm{a}} / \mathrm{m}_{\mathrm{t}}$, where $\mathrm{m}_{\mathrm{a}}$ is the actual mass flow rate and $\mathrm{m}_{\mathrm{th}}$ is the mass flow rate determined from the stagnation pressure $\left(\mathrm{P}_{\mathrm{O}}\right)$ and the stagnation temperature $\left(\mathrm{T}_{\mathrm{o}}\right)$ by means of isentropic flow assumptions. The discharge coefficient is an indication of frictional losses inside the nozzle. Boundary layers that develop and grow along solid walls result in the reduction of the discharge coefficient from an ideal value of 1 , which corresponds to the case when the fluid is frictionless. The calculated values of the discharge coefficients are in the range of 0.5 to 0.8 (see Fig. 3). The most important factor that results in the reduction of the actual mass flow rate below the isentropic value is the presence of friction in real fluids as a result of boundary layer development along solid walls.

The liquid flow rate was varied from $3.154 \mathrm{~g} / \mathrm{s}$ to $18.915 \mathrm{~g} / \mathrm{s}$. The outer air flow rate was varied from $2.85 \mathrm{~g} / \mathrm{s}$ to $10.46 \mathrm{~g} / \mathrm{s}$, corresponding to an air exit velocity of $48 \mathrm{~m} / \mathrm{s}$ to 214 $\mathrm{m} / \mathrm{s}$, respectively. The central air flow was varied from $0.285 \mathrm{~g} / \mathrm{s}$ to $1.046 \mathrm{~g} / \mathrm{s}$, corresponding to an air exit velocity of 159 to $313 \mathrm{~m} / \mathrm{s}$ (sonic conditions at the tube exit). The liquid supply pressure is maintained at a constant 35 psig and regulated by a needle valve with a flowmeter. Droplet size measurements were performed at a distance of $20 \mathrm{~cm}$ downstream from the atomizer exit. The air flow rates are measured by flowmeters with needle valves - a single meter for the central air flow and four meters in parallel for the outer air flow.

Figures 4 and 5 show plots of the droplet Sauter mean diameter when the inner air and outer air are operated separately. In general, the expected trend of decreasing SMD 
with increasing air flow rates is observed. The measurements of the SMD show that the central air flow is much more efficient than the outer air flow at atomizing the liquid. Figures 6 and 7 show the same data plotted as function of air/liquid mass ratio. Note that for a liquid flow rate of $18.93 \mathrm{~g} / \mathrm{s}$, an air to liquid mass ratio of 0.05 is required to obtain a spray SMD of $100 \mu \mathrm{m}$ while operating the inner flow only. An air to liquid mass ratio of 0.7 is required to generate the same $\operatorname{SMD}(100 \mu \mathrm{m})$, at the same liquid flow rate when the outer air is used. Thus, it is seen that, for this particular case, in order to generate the same SMD nearly 14 times more air is required for the annular air flow when compared to the inner air flow. The overwhelming improvement in atomizer performance when using the central air when compared to the outer annular air can be explained by the following three reasons:

a) The outer annular air flow cross sectional area $\left(6.0157 \times 10^{-5} \mathrm{~m}^{2}\right)$ is much larger than the inner air flow cross-sectional area $\left(2.5543 \times 10^{-6} \mathrm{~m}^{2}\right)$. The outer to the inner area ratio is 23.55. This invariably results in larger air velocity at the exit of the central tube when compared to outer annular tube, when the same air flow rate is specified. Larger interface velocity difference between the liquid and the air generally results in improved atomization.

b) When the inner air flow is turned off, the annular liquid flow converts to a cylindrical liquid flow at the exit of the liquid tube. Annular films are inherently less stable than cylindrical columns. This transformation from an annular film flow to a purely cylindrical flow results in an increase of droplet size due the fact that cylindrical columns are more stable than annular columns of liquid.

c) In the central air flow case, the liquid envelops the central air flow shielding, at least initially, the central air flow from contact with the stagnant air. In the outer annular air flow case, the annular air comes in direct contact with the stagnant air immediately at the nozzle exit, thus resulting in a substantial velocity decay.

\section{ACTIVITIES PLANNED FOR NEXT PERIOD}

In the coming months we will continue to study and document the improved performance of the double concentric air assist atomizer. We will primarily undertake the following three tasks:

- Develop breakup models based on the physics of breakup that was observed 
- Map the flow field of the effervescent air-assist atomizer. Use the Malvern laser diffraction instrument for measurement of droplet size in the spray field produced by the double concentric air assist atomizer.

- Vary flow rates of liquid and atomizing air and types of solution. Measure drop size distributions. Determine quality of atomization from microphotography. Establish the relationships between rheological properties of solutions at high shear rates and atomization quality. In particular correlate the data in terms of both shear and extensional properties of the polymeric solutions. 


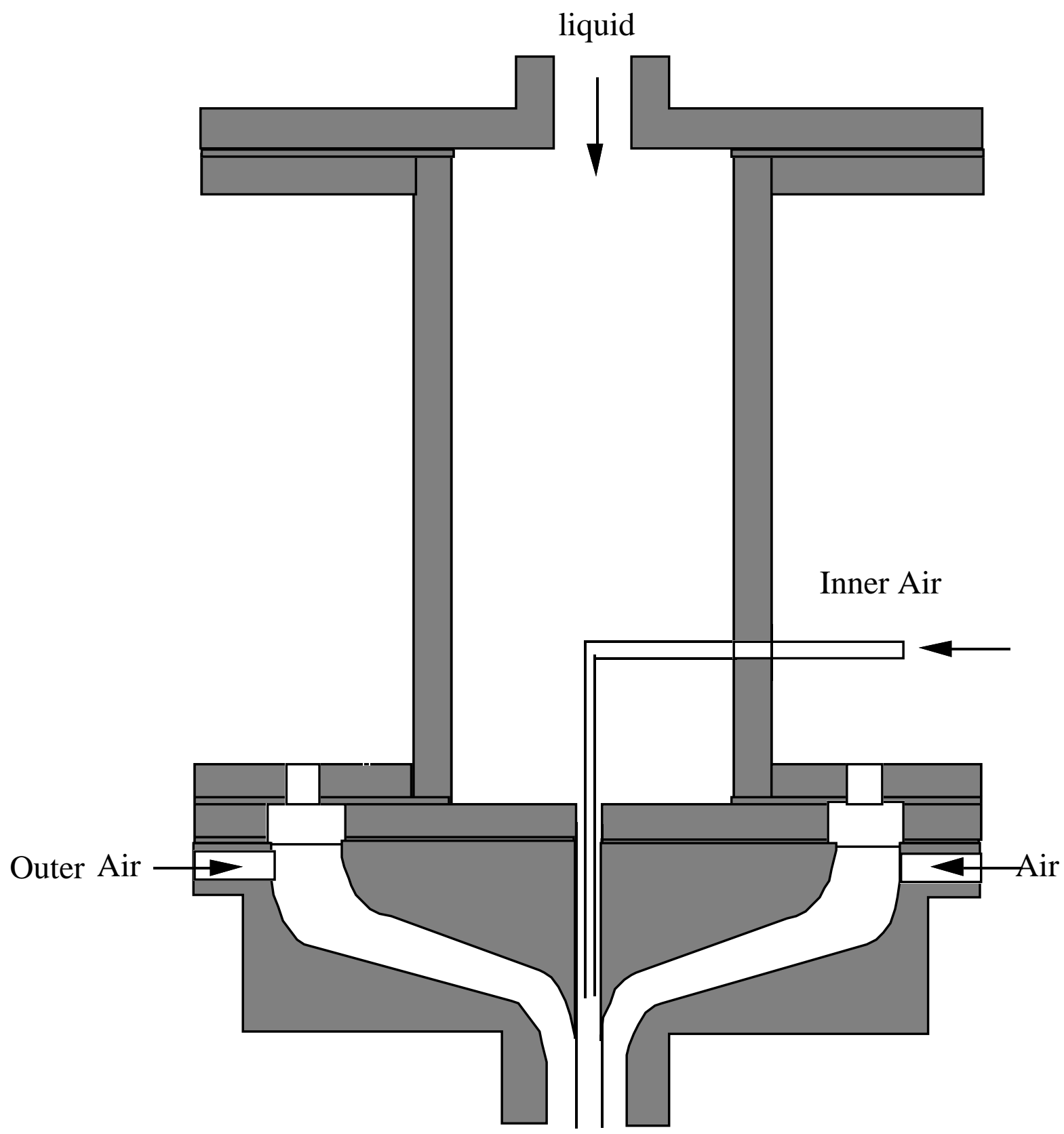

Fig. 1 The Double Concentric Nozzle 


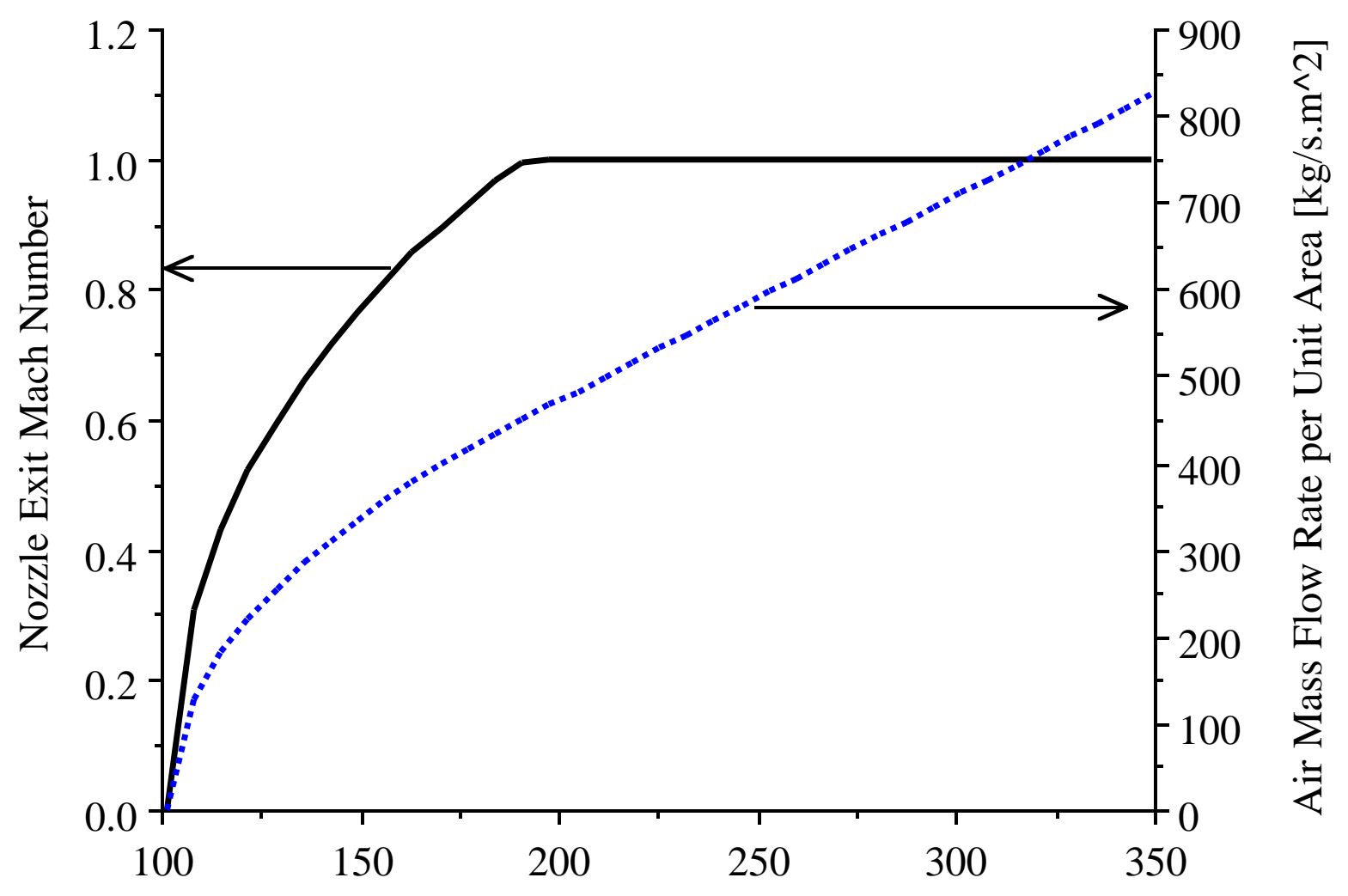

Stagnation Pressure Po [kPa]

Fig. 2 Air mass flux and Nozzle exit Mach number $M_{1}$ vs. stagnation pressure $P_{0}$. 


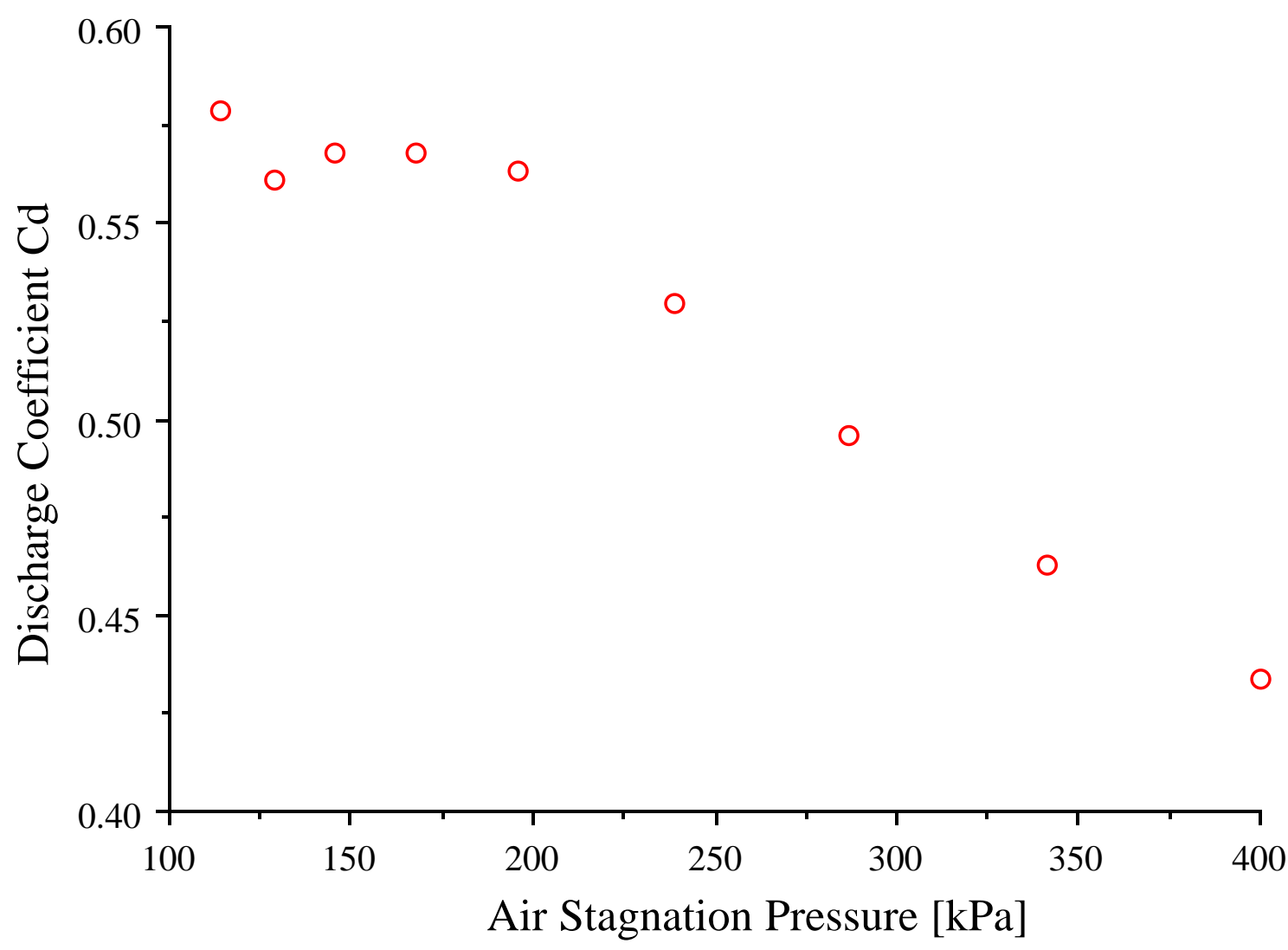

Fig. 3 Effect of air Stagnation Pressure on Discharge Coefficient of the central tube 


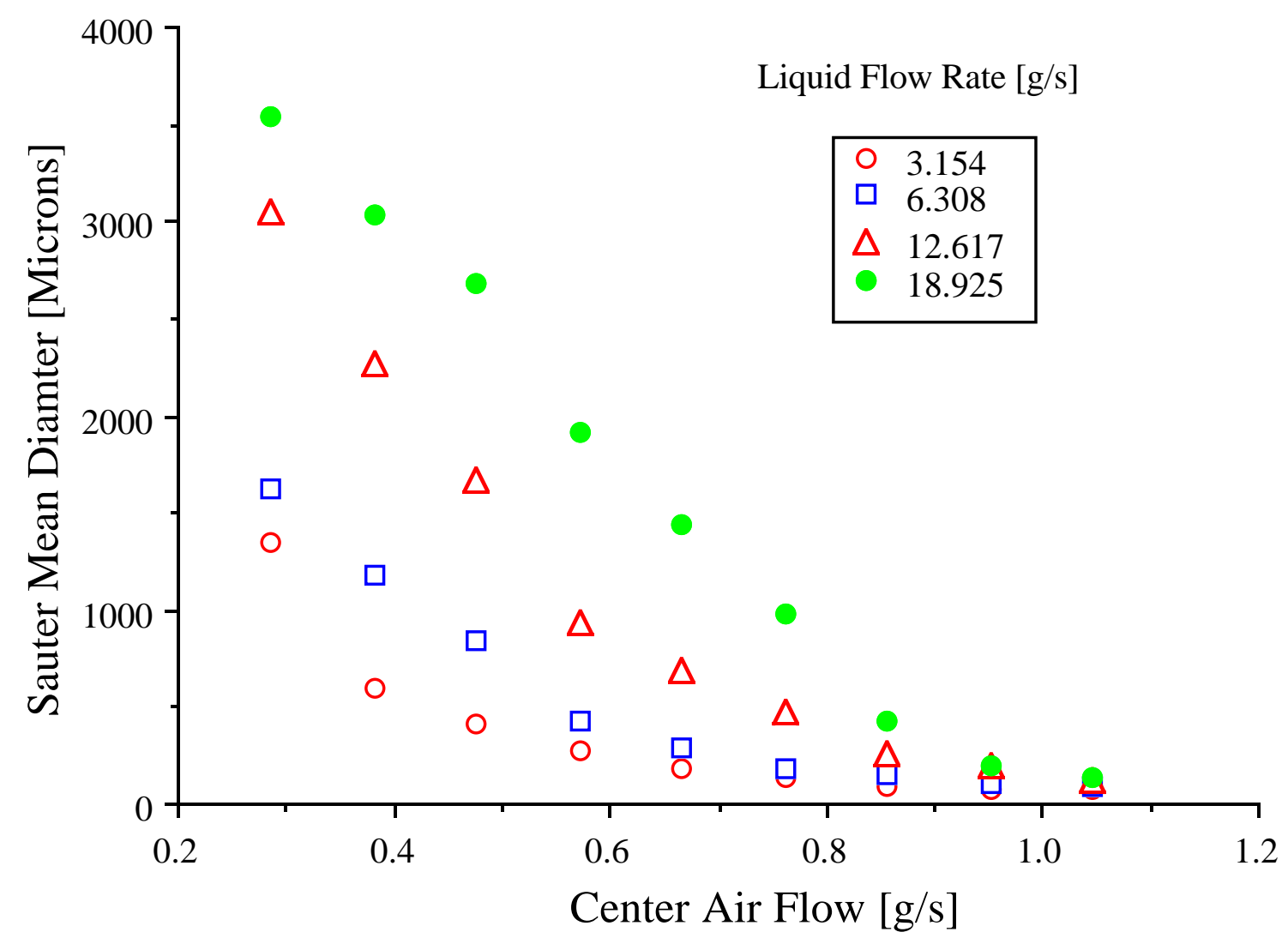

Fig. 4 Effect of the inner air mass flow rate on Sauter mean diameter at different liquid flow rates 


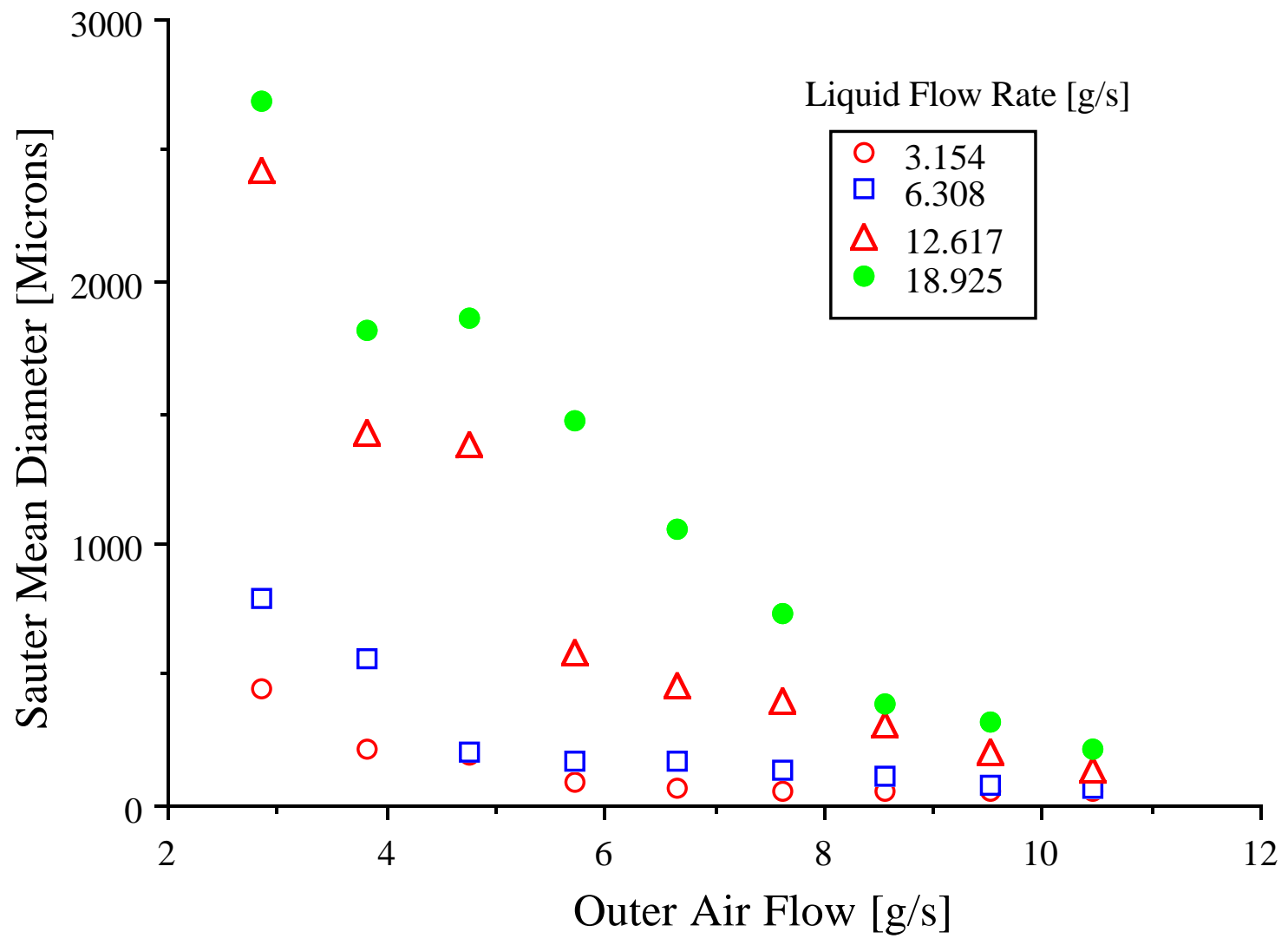

Fig. 5 Effect of the outer air mass flow rate on Sauter mean diameter at different liquid flow rates 


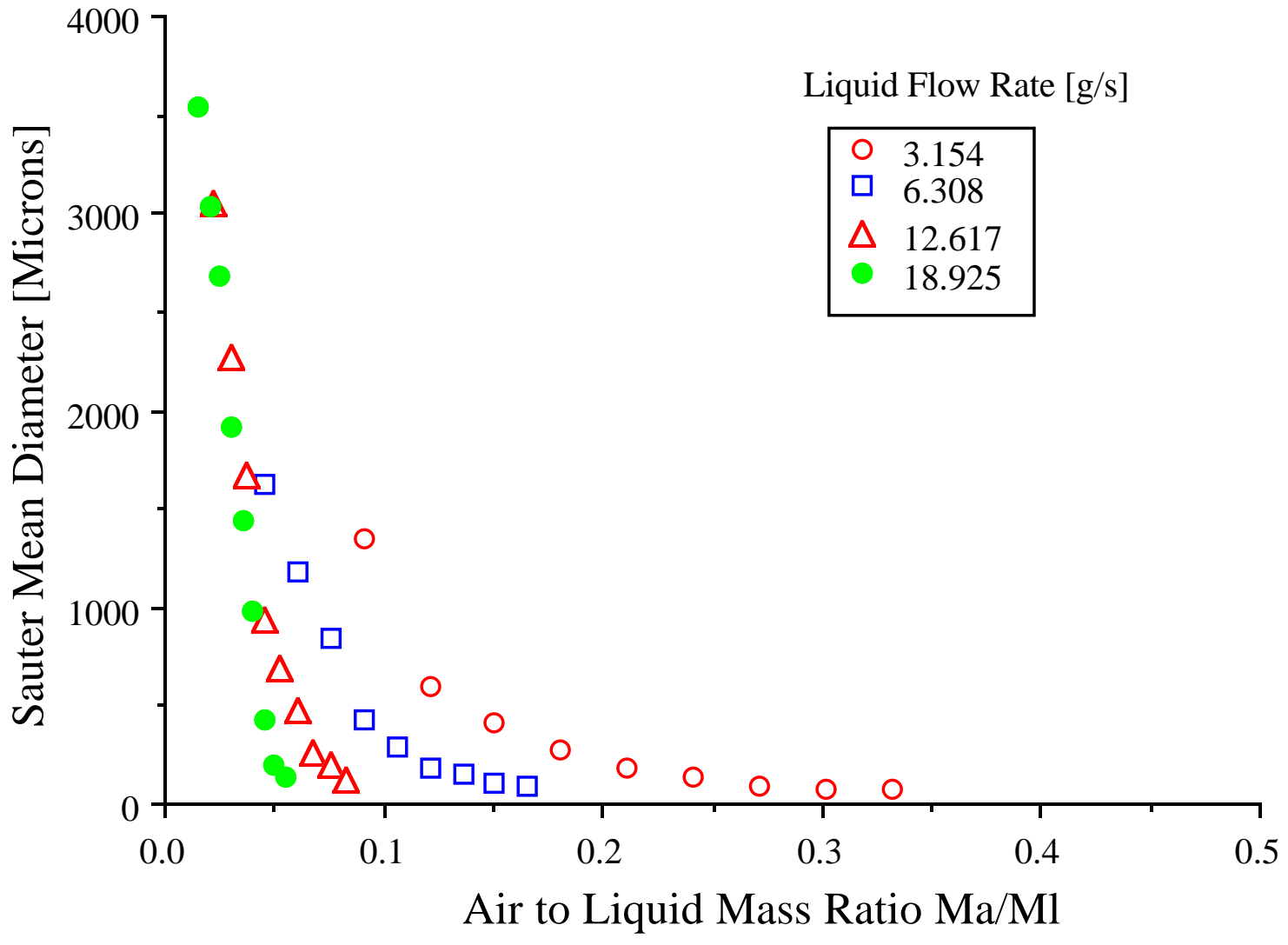

Fig. 6 Effect of the air/liquid mass ratio on Sauter mean diameter at different liquid flow rates for the central air flow 


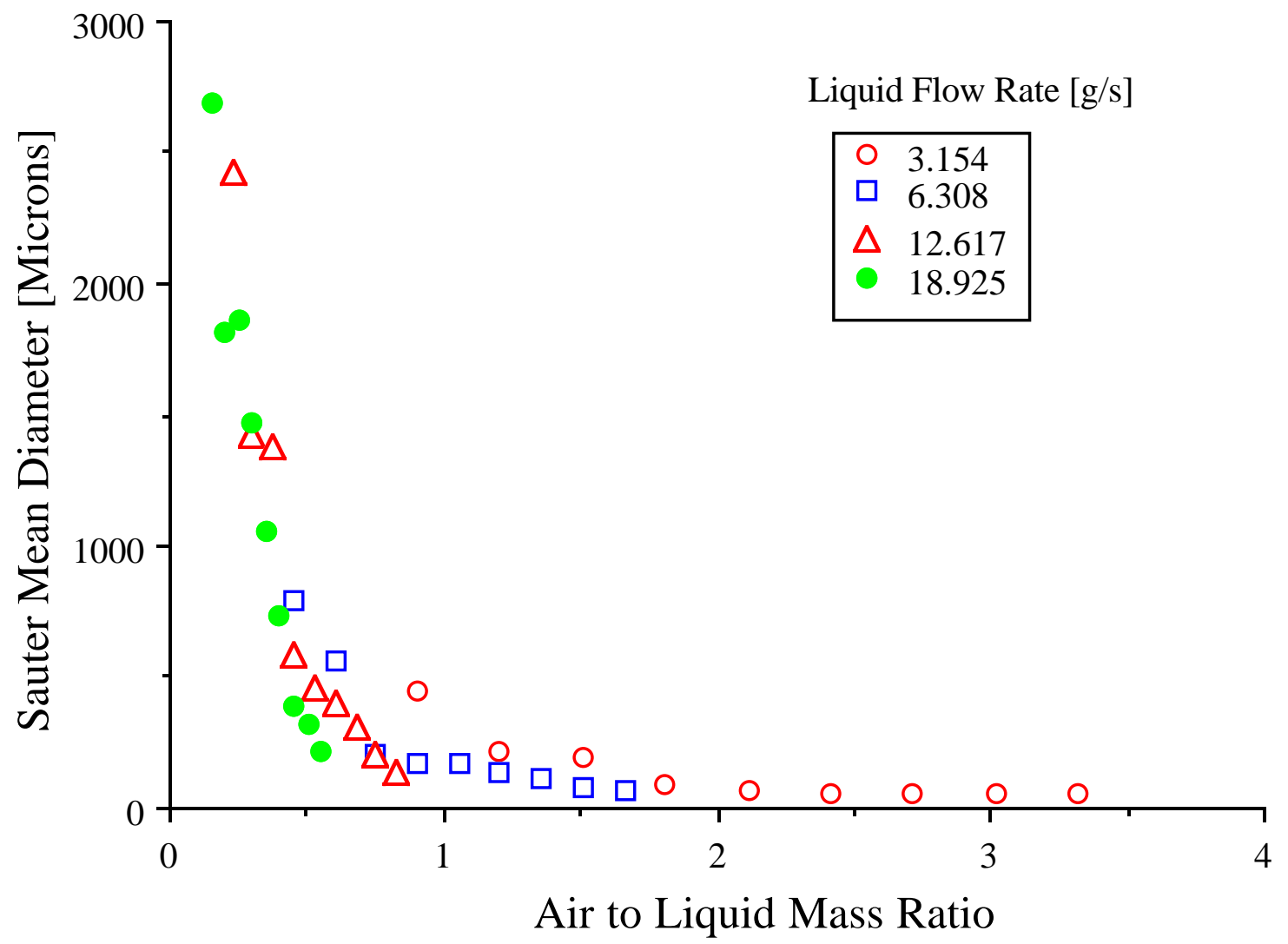

Fig. 7 Effect of the air/liquid mass ratio on Sauter mean diameter at different liquid flow rates for the outer air flow 